\title{
¿Quién manda en la comunidad? Percepciones de estudiantes sobre el poder, los actores políticos y el Estado
}

\author{
SALVADOR MARTÍ I PUIG
}

Se presenta el análisis de una experiencia docente durante el curso 2012-2013 con estudiantes de la Universidad Veracruzana Intercultural, sede Las Selvas. En primer lugar, se expone el contexto de la Universidad, la dinámica docente y el plan de estudios desplegado. Después se muestran las reflexiones y los hallazgos de los estudiantes sobre su percepción del poder, los actores políticos, las instituciones y el Estado desde su cotidianidad y su entorno multicultural. Por último, se interpretan las formas de los jóvenes de concebir el poder y su visión desconfiada y ambigua sobre el Estado y las instituciones públicas.

PALABRAS CLAVE: educación intercultural, jóvenes, presencia del Estado, actores políticos, confianza, cultura política

Who's in Charge in the Community? Perceptions of Students on Power, Political Actors, and the State

We offer an analysis of a course taught during the 2012-2013 academic year to students from the Intercultural University of Veracruz. The article describes the context of the University, its teaching methods, and the subjects offered. Then, the article identifies students' perceptions of power, political actors, institutions, and the State according to their everyday reality and multicultural environment. Finally, as a result of the findings, the article interprets the ways in which the youngsters conceive power and their mistrusting and ambiguous vision of the State and public institutions.

KEYWORDS: intercultural education, young people, State presence, political actors, trust, political culture

\footnotetext{
SALVAdor MARTí I PUIG

Universidad de Girona, 


\section{Presentación de la investigación}

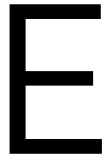

ste texto presenta el resultado de una experiencia docente y de investigación con un grupo de estudiantes de segundo semestre de la Universidad Veracruzana Intercultural (UVI), sede Las Selvas, de la licenciatura de gestión intercultural, pertenecientes a las especialidades de derecho, salud, medio ambiente y lenguas. La experiencia se basó en el desarrollo de un curso de ciencia política. El objetivo fue trabajar con los estudiantes un conjunto de conceptos y herramientas analíticas para describir, explicar y debatir la realidad política del país y de su entorno, a partir de su experiencia cotidiana. ${ }^{1}$

El curso se desarrolló durante diez meses, de septiembre de 2012 a junio de 2013, de manera presencial, una semana al mes. Además de las sesiones presenciales, para el desarrollo efectivo y satisfactorio del curso fue necesario que los estudiantes realizaran, entre sesión y sesión, lecturas, tutorías en línea, entrevistas a personas de su comunidad y otras actividades de trabajo de campo diseñadas y organizadas en las sesiones. Cada seminario tuvo una sesión teórica y una sesión práctica en el aula.

En este artículo se señalarán los contenidos de la parte teórica, y lo más importante, las aportaciones fruto de las reflexiones y de los datos obtenidos por los estudiantes en el trabajo de campo. Esto último es lo que da sentido

$1 \quad$ Agradezco la disposición del director de la sede Las Selvas, al cuerpo docente y a los estudiantes que participaron en el curso-taller. Sin la generosa acogida de todos los miembros de la uvı, hubiera sido imposible desarrollar este trabajo. También agradezco a la Universidad de Salamanca por darme la posibilidad de gozar de un año sabático, durante el que pude hacer la estancia, y a la Agencia Española de Cooperación Internacional y Desarrollo por el financiamiento del Programa de Cooperación Interuniversitario "Educación Superior Intercultural” para desarrollar el trabajo de campo. Debo hacer una mención especial de la Universidad Autónoma Metropolitana-Xochimilco por haberme concedido la Cátedra "Óscar Uribe Villegas", con la cual pude trabajar y discutir el tema del poder y el Estado en México. 
al texto, pues pretende dar voz a las inquietudes y percepciones de los estudiantes de la UVI, jóvenes inquietos, listos e inteligentes. Es preciso indicar que este trabajo no pretende teorizar sobre las opiniones de los estudiantes a partir de hipótesis preconcebidas ni es un trabajo etnográfico en el que se haga una descripción densa de los estudiantes en el aula. La pretensión es más humilde. Se trata de exponer una experiencia docente basada en las opiniones y diálogos de y entre los estudiantes sobre su realidad política. Es posible que para muchos académicos este trabajo sea descriptivo en exceso, sin embargo, creo que conocer mediante las experiencias de un curso la opinión de los estudiantes acerca de una institución superior intercultural sobre el poder, el Estado, las instituciones, los actores políticos y su condición multicultural es, en sí mismo, una aportación relevante (Van Dijk, 2001).

Como se ha señalado, el objetivo del curso era exponer los temas fundamentales del corpus clásico de la ciencia política. ${ }^{2}$ Los estudiantes tuvieron que leer varios textos y reflexionar sobre ellos, realizar actividades prácticas relacionadas con su entorno a la luz de las lecturas, con el fin de recabar información que más tarde se comentó y se discutió entre todos. El contenido del curso se muestra en el cuadro 1.

El espíritu del seminario era debatir sobre tres temas cruciales relacionados con la realidad política que viven los estudiantes. A saber:

- Cómo se percibe el poder y los actores que participan en la política.

- Cómo se ve al Estado en la vida cotidiana.

- Cuáles son los temas que más les preocupan y cuál es la confianza que tienen en las instituciones.

Estos tres temas — que se abordaron y discutieron a lo largo del curso- son los que se desarrollan en los apartados que siguen. Es preciso señalar las características de los estudiantes que estuvieron en el aula.
La mayoría era de segundo semestre, sus edades oscilaban entre los 18 y 20 años. Por estar en segundo semestre de la licenciatura, estudiaban el tronco común y al finalizar ese año debían decidir cuál sería su especialización: comunicación, derechos, lenguas, salud o sustentabilidad.

\section{EL CONTEXTO DE LA INTERVENCIÓN}

Desde 2007, la UVI, que es una dirección de la Universidad Veracruzana (UV), surge como una iniciativa pionera de institucionalización de nuevos cauces de diversificación epistémica. ${ }^{3}$ La UVI conjuga, por un lado, un esfuerzo de descentralización académica en sus cuatro sedes ubicadas en regiones interculturales del estado de Veracruz - Huasteca, Totonacapan, Grandes Montañas y Selvas-, y por el otro, un impulso a la redefinición y reestructuración interdisciplinaria de las actividades docentes, de investigación y vinculación (UVI, 2005). Según Dietz (2008: 2012), uno de los promotores-ideólogos de la institución, ésta fue una apuesta novedosa por la descolonización e interculturalización de los procesos de producción, adquisición y distribución de los conocimientos universitarios. Además, desde su

2

El material para el curso se basó en un manual realizado por Josep Maria Vallès y Salvador Martí i Puig, titulado Curso de ciencia política (Vallès y Martí i Puig, 2000). Se puede obtener en el apartado Teaching Documents de la web, en <https://girona.academia.edu/SALVADORMARTI PUIG>.

3 La UVI comenzó sus actividades en 2005 como Programa Intercultural. En 2006 se constituyó como Dirección General de la Universidad Veracruzana Intercultural y en 2007 elaboró y puso en marcha un plan de estudios, con base en el cual se imparte la licenciatura de gestión intercultural para el desarrollo, vigente al día de hoy (UVI, 2007). Para mayor información, véase la página institucional de la uvı, en <http://www.uv.mx/uvi/>. Para una visión regional de la educación superior multicultural en Latinoamérica, véase Mato (2008). 


\begin{tabular}{|c|c|c|}
\hline Sesión & Tema & Tareas de los estudiantes \\
\hline 1 & Presentación del curso a los profesores de la uVI. & \\
\hline 2 & Presentación del curso a los estudiantes inscritos. & $\begin{array}{l}\text { Inscribirse y comprometerse a asistir a las } \\
\text { sesiones y a realizar las tareas. }\end{array}$ \\
\hline 3 & $\begin{array}{l}\text { Qué es la política y dimensiones de la política. Quién } \\
\text { hace política -individuos y actores colectivos- } \\
\text { y cómo. }\end{array}$ & $\begin{array}{l}\text { Preguntar -y reflexionar al respecto- quién } \\
\text { hace política en la comunidad. Cómo se hace. } \\
\text { A quién va dirigida y cómo se puede calificar. }\end{array}$ \\
\hline 4 & $\begin{array}{l}\text { El poder y sus fuentes. La legitimidad y la obediencia. } \\
\text { Diversas teorías sobre el poder. }\end{array}$ & $\begin{array}{l}\text { Señalar quién manda y por qué en la familia, la } \\
\text { comunidad o municipio y la región. Reflexionar } \\
\text { por qué se obedece. }\end{array}$ \\
\hline 5 & $\begin{array}{l}\text { La participación política. ¿Cuándo participa la gente? } \\
\text { Los elementos explicativos de la participación y la } \\
\text { movilización. }\end{array}$ & $\begin{array}{l}\text { Realizar entrevistas sobre procesos de } \\
\text { participación y movilización en la comunidad. } \\
\text { Aportar experiencias para debatir. }\end{array}$ \\
\hline 6 & $\begin{array}{l}\text { El Estado. Elementos, rasgos y evolución. La } \\
\text { administración del Estado en el territorio, ayer y hoy. }\end{array}$ & $\begin{array}{l}\text { Exponer cuándo y cómo uno se encuentra con } \\
\text { el Estado en la vida cotidiana. Qué diferencias } \\
\text { existen respecto de la relación con los } \\
\text { "mayores" de la comunidad. Qué da, pide, quita } \\
\text { y regula el Estado. }\end{array}$ \\
\hline 7 & $\begin{array}{l}\text { Cultura política y sus elementos. Las percepciones } \\
\text { de los ciudadanos sobre las instituciones, autoridades } \\
\text { y políticas públicas, y sobre "uno mismo" como } \\
\text { actor político. La cultura política cívica, clientelista } \\
\text { y parroquial. }\end{array}$ & $\begin{array}{l}\text { Hacer cuatro encuestas - a dos compañeros } \\
\text { y a dos "mayores"- sobre las percepciones } \\
\text { acerca de aquellos elementos clave de la cultura } \\
\text { política, con el fin de analizar la cultura política } \\
\text { local. Responder la encuesta (véase el anexo). }\end{array}$ \\
\hline 8 & $\begin{array}{l}\text { Identidad, ciudadanía y política. Elementos } \\
\text { de la identidad. Vinculación entre el ciudadano } \\
\text { y el Estado. La Constitución y los derechos de } \\
\text { los ciudadanos. }\end{array}$ & $\begin{array}{l}\text { Reflexionar sobre los derechos que expone la } \\
\text { Constitución y la relación entre lo que se expone } \\
\text { y la realidad. Pensar y realizar entrevistas sobre } \\
\text { la identidad. }\end{array}$ \\
\hline 9 & $\begin{array}{l}\text { La comunidad y la vida cotidiana como espacio } \\
\text { de participación. Los conceptos de derechos } \\
\text { y empoderamiento. }\end{array}$ & $\begin{array}{l}\text { Buscar dos políticas públicas sectoriales } \\
\text { específicas con incidencia en la comunidad } \\
\text { y analizarlas -en su diseño, regulación } \\
\text { e implementación-. Evaluar su impacto } \\
\text { y ver cómo podrían mejorarse. } \\
\text { Reflexionar sobre la comunidad realmente } \\
\text { existente y la comunidad posible. }\end{array}$ \\
\hline
\end{tabular}

Fuente: Elaboración propia.

fundación, la UVI se organizó por medio de vínculos con actores indígenas pertenecientes a los movimientos veracruzanos — sobre todo, del Consejo Regional Indígena del Pueblo Nahua y Popolucay con ello se reivindicó el necesario carácter indígena, náhuatl o popoluca, de la nueva institución superior (Mateos y Dietz, 2014).

Desde su nacimiento, la UVI se ha centrado en la génesis de nuevos campos de conocimiento en torno a la interculturalidad y la sustentabilidad, con énfasis en la biodiversidad de los ecosistemas circundantes y la gestión del patrimonio que identifica las zonas y que diversifica en términos culturales, étnicos y lingüísticos a los habitantes. El objetivo de la UVI es generar, aplicar y transmitir conocimiento mediante el diseño e implementación de programas educativos con enfoque intercultural, centrados en el aprendizaje situado y la investigación 


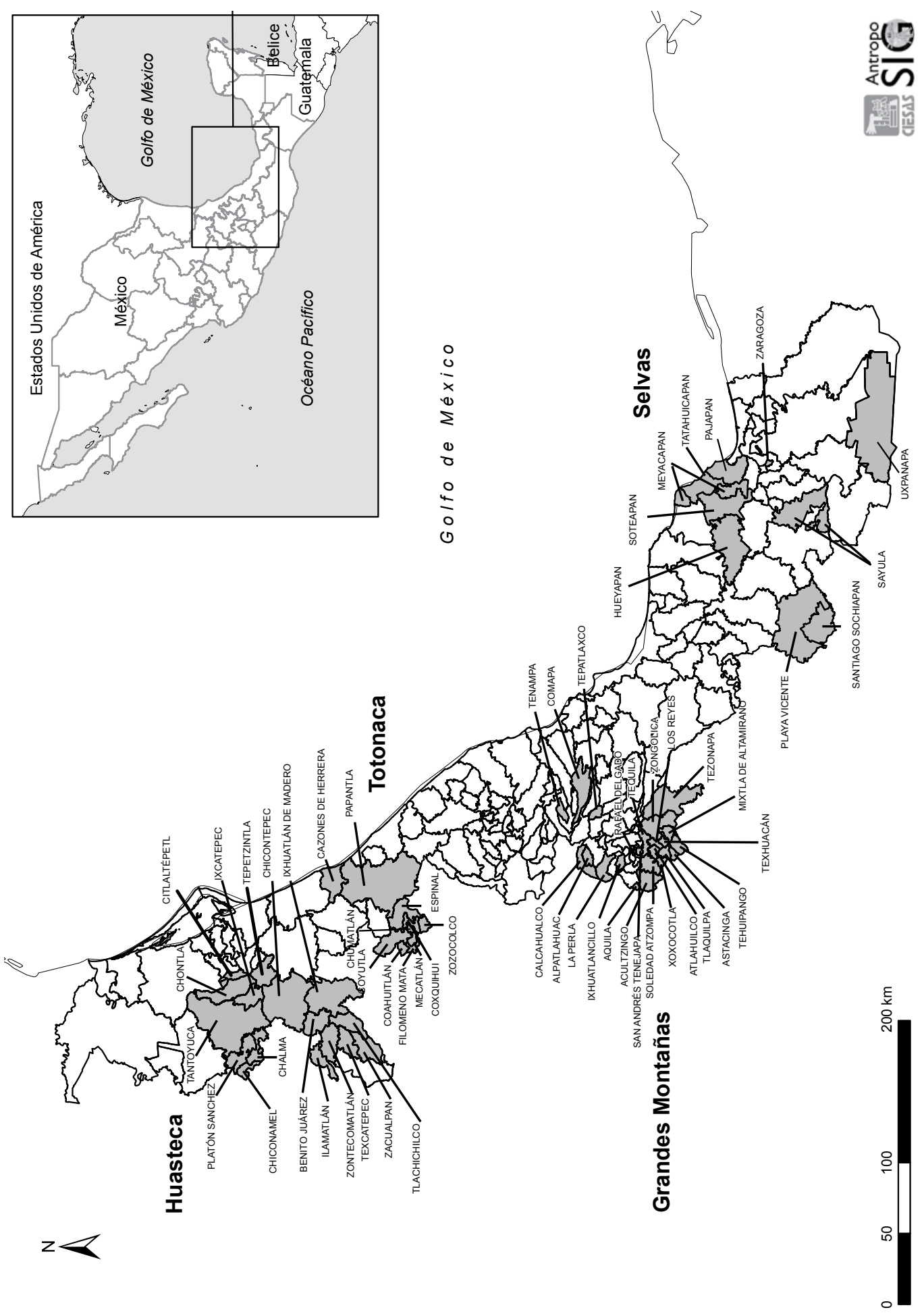

Mapa 1. Sedes de la Universidad Veracruzana Intercultural. Fuente: Antroposig-CIESAS. 
vinculada, al mismo tiempo que se procura el diálogo de saberes y se promueve una mejor calidad de vida mediante la sustentabilidad y el fortalecimiento de las lenguas y culturas del estado de Veracruz. Con dicha pretensión, la UVI ofrece la licenciatura de gestión intercultural para el desarrollo (LGID) con cinco orientaciones: comunicación, derechos, lenguas, salud y sustentabilidad.

La sede Las Selvas se encuentra en la comunidad de Huanzuntlán, enclavada entre los municipios de Mecayapan, Pajapan, Soteapan y Tatahuicapan, todos en el sur del estado de Veracruz. Se trata de una región costera-ganadera, pesquera y agrícola. Cuenta con una población indígena hablante de lengua náhuatl, sin embargo, en la sede se pueden escuchar conversaciones en zoque-popoluca, zapoteco, chinanteco, náhuatl y mixe. A la par de la riqueza cultural y lingüística de la zona, las características socioeconómicas de la población son de gran vulnerabilidad. Según los datos oficiales, en Soteapan, el porcentaje de población en situación de pobreza alimentaria es de $75.2 \%$, el de población en situación de pobreza de capacidades es de $81.8 \%$ y el de población en situación de pobreza de patrimonio es de $92.7 \%$. Una proporción de $45.1 \%$ de la población mayor de 15 años es analfabeta y $65.4 \%$ no terminó la primaria. Para Pajapan los datos son semejantes, aunque más moderados: el porcentaje de población en situación de pobreza alimentaria es de $57.7 \%$, el de población en situación de pobreza de capacidades es de $67.4 \%$ y el de población en situación de pobreza de patrimonio es $86.1 \%$; 34.7\% de la población mayor de 15 años de edad es analfabeta y $61.3 \%$ no tiene la primaria completa. En Tatahuicapan y Mecayapan, con otro tipo de datos en el informe municipal, también el paisaje es crítico: $38.1 \%$ de la población vive en condiciones de pobreza moderada y $51.6 \%$ en condiciones de pobreza extrema. Sólo $1.7 \%$ de la población es no pobre y no vulnerable. Es fácil deducir que hablamos de un contexto no sólo multicultural y plurilingüe, sino también vulnerable, con familias con pocos recursos económicos, y como lo califican los informes, con un alto grado de marginación.

A sabiendas de esta realidad, es preciso señalar que en la UVI hay un compromiso para implicar y vincular a los estudiantes. La institución involucra a los estudiantes con las comunidades a partir de sus trabajos de investigación para que comprendan y mejoren las condiciones de vida, además de comprometerlos con su cultura, lengua y conocimiento tradicional (Mateos y Dietz, 2014: 56). Por este motivo, el equipo de docentes de la UVI pensó que desarrollar un curso de ciencia política podía tener triple utilidad para los estudiantes. Por un lado, para que reflexionaran sobre la relación entre su realidad local y la realidad nacional, por otro, para que advirtieran cómo las políticas públicas diseñadas por las autoridades tienen un impacto en su quehacer cotidiano, y por último, para que se descubrieran como actores políticos activos.

\section{Percepciones sobre la política, el poder y quienes hacen política ${ }^{4}$}

Para cualquier ciudadano el término "política" es familiar. La política forma parte del lenguaje cotidiano, pero la familiaridad con la palabra no implica un conocimiento profundo de su significado ni que quienes la usan la entiendan del mismo modo. Sin duda, "política" es un término con muchos registros, dotado de sentidos diferentes según el ámbito y el momento en que se aplica (Vallès y Martí, 2015).

En este texto partimos de que la política es una práctica por lo general colectiva, cuya finalidad es regular conflictos entre grupos. Su resultado es la adopción de decisiones que obligan — por la

$4 \quad$ El concepto y definición de política y poder que se exponen en este epígrafe se comparte y extrae de Vallès (2000). 
fuerza, si es preciso- a los miembros de la comunidad. También se ha debatido mucho sobre el origen de la política. Según Janos (citado en Vallès, 2000), el origen de la política es "la diferencia convertida en desigualdad”. Por esta razón, la política ha sido considerada como la "gestión de las desigualdades sociales”, mas no su solución. En este sentido, es posible afirmar que las diferencias entre grupos sociales generan relaciones asimétricas de las que nacen tensiones que requieren un tratamiento político.

De lo expuesto se puede deducir que la característica fundamental de la política es el conflicto en un mundo de recursos escasos y mal repartidos, y la existencia de preferencias disímiles. Es decir, se basa en un mundo en el que no todos piensan igual, no tienen las mismas riquezas, gustos y oportunidades. Así, los que creen que merecen más, luchan para obtener más; los que ya tienen bastante o mucho no quieren cambiar las cosas. Pero la política no sólo es conflicto y lucha, también es "regulación" de este conflicto. Regulación no significa "solución”, pero sí capacidad de generar una decisión que debe ser respetada una vez tomada, al menos por un tiempo. Sin embargo, para llevar a cabo la "regulación" es necesario que personas o instituciones tengan un elemento clave: poder. ¿Cómo se define el poder?

Una definición útil es la que lo equipara a la capacidad de intervenir en la regulación del conflicto social. Otra manera de definirlo es como "aquello que hace que una(s) persona(s) hagan cosas que no harían de otra forma”. ¿Dónde nace esta capacidad de intervención? Quienes han reflexionado sobre este fenómeno exponen que el poder político tiene tres componentes: fuerza, influencia y autoridad. Con la fuerza se puede generar miedo; con la autoridad, respeto, y con la influencia, capacidad de convencer.

La reflexión sobre los conceptos expuestos es vital para comprender dos cuestiones clave en la vida cotidiana de las personas y las comunidades: quién tiene el poder en nuestro entorno y por qué obedecemos. Éstas fueron las primeras preguntas que se formularon en el aula de la UVI después de las sesiones tercera y cuarta. Las cuestiones que se plantearon a los estudiantes - cuyas respuestas se sistematizan en los cuadros 2 y 3 - fueron las siguientes:

- ¿Quién creen que tiene el poder en los espacios que conforman su vida cotidiana — familia, comunidad y municipio o región-?

- ¿Por qué ésos que lo detentan "tienen" el poder?

- ¿Cuáles son las fuentes de ese poder?

Se observa que en el ámbito familiar pervive una concepción machista, patriarcal y economicista del poder. Se trata de un poder asociado al dominio, la fuerza, la tradición y el control de recursos materiales. Esta concepción cambia o se atenúa por la ausencia del varón - debido a la migración - o cuando la mujer entra en el mercado laboral y obtiene recursos que le otorgan autonomía. Ante esta situación, los estudiantes justifican la realidad diciendo: "mi abuelito —el varón mayor-, en las cenas de año nuevo, siempre dice que él es el jefe de la familia", "la mujer tiene que lavar la ropa, los trastes y dedicarse a las labores del hogar". Sin embargo, una porción relevante - aunque no mayoritaria- de las estudiantes empieza a cuestionar este modelo y señala que estudia para progresar, trabajar, ganar dinero para aportar a la familia y tener "su lugar". En ese sentido, es importante señalar que estas estudiantes seguramente serán la primera generación de mujeres de la comunidad con formación superior, por lo tanto, deberán abrirse camino hacia la autonomía en un entorno tradicionalmente machista. Este proceso, que no será fácil, será inexorable. Así se manifestaba en el aula cuando se exponían temas de violencia intrafamiliar y las alumnas se indignaban, mientras los varones callaban o esbozaban una sonrisa burlona.

Otra cuestión es el cambio de escala al hablar de poder. Si bien en el nivel doméstico se percibe que el poder reside en el varón y se tiene una 


El varón mayor
El jefe del hogar
Mi padre

Provee de recursos

Tiene más sabiduría y edad

Es un hombre, no una mujer

Revisa, ordena todas las actividades para que se realicen

adecuadamente y pone un reglamento que debe ser respetado por todos los integrantes de la familia

El padre representa a toda la familia

Es quien da permiso para salir y participar en eventos

\begin{tabular}{lll}
\hline Mi madre & Mi padre ya no vive & Por sustitución \\
& Mi padre emigró & Emergencia de una nueva \\
& Mi padre ya no está con ella & autoridad \\
& Mi madre también es capaz & Dinero -acceso de los dos \\
Mi padre y mi madre & Administran el dinero y el hogar juntos & al dinero-
\end{tabular}

Dinero

Edad

Conocimiento

Tradición

Machismo

Fuerza

Fuente: Elaboración propia.

CUADRO 3. EL PODER EN LA COMUNIDAD Y EN EL MUNICIPIO

Tipo de actor

Personas

\begin{tabular}{ll} 
& Agente municipal \\
& Presidente municipal \\
& Comisario ejidal \\
\hline Organizaciones & Antorcha Campesina \\
& Grupo priísta \\
& Partido [Revolucionario \\
& Institucional] \\
& Mesa del cabildo \\
\hline Colectivos ciudadanos & Comités de barrio, agua, \\
& luz, salud, educación, \\
& limpieza, caza, ganaderos \\
& Comité de manzana \\
& - secretario, tesorero \\
& y presidente-
\end{tabular}

\section{Por qué tiene el poder}

Son importantes

Son los que siempre mandan

Controlan las redes de "promotores" de los programas sociales

Son elegidos por las personas que asisten a las juntas mensuales de manzana Elaboran y convocan a tareas comunales Ponen multas a quien no participa Desean el bien común

\section{Las fuentes del poder}

Tradición

Ley

Dinero

Confianza de la comunidad

Organización de los pobladores

Dinero para campañas Conexiones con los de arriba -en Xalapa-

\section{Resistencia civil}

Capacidad de organización y de movilización frente a las autoridades Confianza - conocen lenguas maternas y las necesidades de la comunidadTienen formación - primaria y secundaria-

Fuente: Elaboración propia.

concepción de dominio, en la comunidad y el municipio la importancia del dinero y la tradición se atenúa. Eso no quiere decir que al señalar a las personas u organizaciones más poderosas no aparezcan las que tienen más recursos, sino que también se contemplan los colectivos sociales populares que disponen de recursos organizativos y simbólicos, capaces de realizar movilizaciones.

Sobre el tema del poder en la comunidad, a pesar de criticar a las autoridades partidarias o a los caciques, los estudiantes por lo general expresaban una visión de relativa armonía y usaban términos 
como tradición, consenso, ley, usos y costumbres; no tanto dinero o fuerza. Les pregunté hasta qué punto era cierto que en el ámbito familiar el poder era puro dominio del varón y en el comunitario era consenso y buena fe, y se empezó a gestar una discusión. Después de discutir sobre el tema, se moderó la concepción autoritaria de la familia a la par que se desdibujó un poco la percepción armoniosa de la comunidad. La conclusión fue que al día de hoy la vida en comunidad no es tan plácida ni la familia tan rígida, a pesar de los estereotipos.

\section{Cómo se ve el Estado y cómo se manifiesta en la vida cotidiana}

El otro gran tema que se debatió fue el Estado. Se presenta como la forma de organización política dominante desde su aparición en Europa a finales de la edad moderna y en Latinoamérica durante la Colonia y los procesos de independencia (Centeno y Ferraro, 2013). Desde entonces, el Estado se convirtió en la forma de organización política dominante en un territorio y sobre la población que vive ahí. El Estado, como lo define Max Weber (2003), es el actor que reivindica la exclusividad de la coacción por medio de la creación del derecho. En efecto, el Estado es el agente que gestiona la administración de la violencia física a partir del control del ejército, la policía, las cárceles y las sanciones físicas o pecuniarias. Con base en este control, el Estado dice garantizar determinados derechos y libertades, presta servicios a la comunidad y extrae recursos. Sin embargo, el Estado, en algunos territorios de Latinoamérica, no ha actuado como se presenta en los libros. En México, como en otros países de la región, hay territorios en los que la presencia del Estado es reciente, precaria o incluso ausente.

Esta ausencia o débil presencia de la autoridad del Estado en un trozo del territorio mexicano no deja de sorprender a quienes tienen una mirada eurocéntrica de la política. Sin embargo, en México, el Estado no funciona igual en los barrios acomodados de la capital, en la periferia urbana o en las zonas rurales alejadas del centro (Martí i Puig, 2009). No se puede comparar la presencia del Estado en gasto público, seguridad o atención en el elegante entorno capitalino de la Condesa con el barrio periférico xalapeño de Castillo. A su vez, el respeto a los derechos humanos en algunas delegaciones del Distrito Federal no tiene nada que ver con la impunidad que reina en otras latitudes, como en los estados de Michoacán, Guerrero o Veracruz.

Al observar las diferencias entre los países de Latinoamérica, es fácil deducir que la implantación del Estado no se ha hecho de la misma manera, por lo tanto, la ciudadanía significa cosas diferentes en un sitio o en otro. El acceso a la justicia, las oportunidades educativas o sanitarias, y hasta el ejercicio de derechos como los de libertad de expresión y de reunión o el habeas corpus son diferentes en función del lugar donde se viva y del estrato social al cual se pertenezca en el mismo país. Por ello, los analistas Méndez, O’Donnell y Pinheiro (1996) hablan de la existencia de "zonas grises" en las que la presencia del Estado es acotada e irregular y la protección de los derechos es limitada.

Se puede añadir a esta tesis que otras instancias ocupan los lugares de poder que el Estado deja vacíos. En Latinoamérica, en algunas ocasiones a lo largo de la historia, el Estado se ha abstenido de ejercer la soberanía, ya sea por lejanía o desinterés, o porque esa tarea es asumida por entidades privadas, sobre todo caciques y terratenientes, que tienen la potestad de controlar los recursos y a las personas que se hallan en sus fincas. Otras veces porque las comunidades indígenas se autorregulan sin necesidad, ni voluntad, de acudir al Estado.

Vale la pena mencionar una obra de Miguel Ángel Centeno (2002), titulada Blood and Debt. War and the Nation State in Latin America. Centeno expone que a las elites latinoamericanas nunca les 


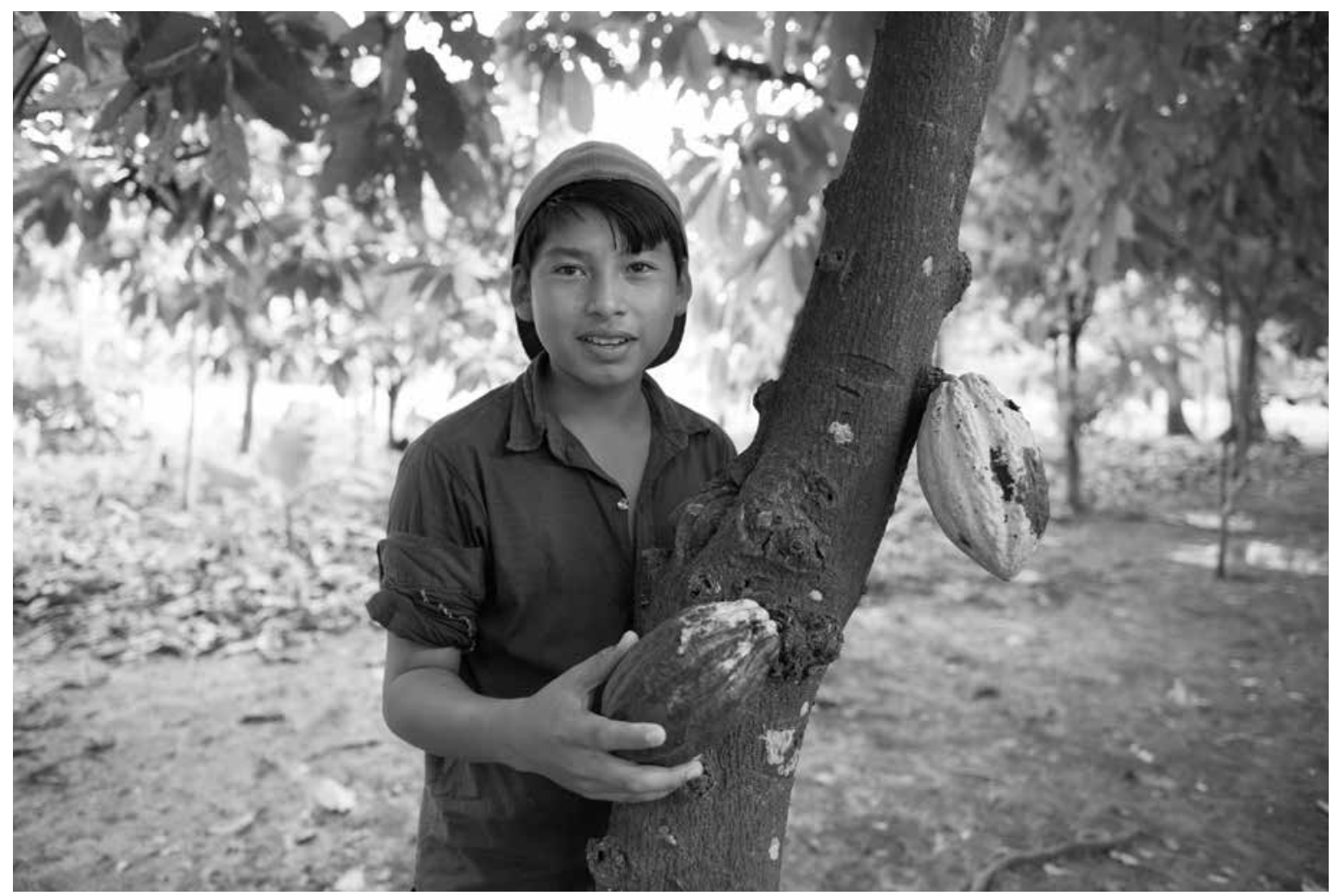

RodRIGo GonZÁLEZ • Jornalero del cacao. Las haciendas cacaoteras en Tabasco están recuperando vitalidad después de que una plaga de hongo terminara con miles de hectáreas de cacao. Tabasco, México, noviembre de 2015.

interesó erigir administraciones civiles sólidas que se extendieran alrededor del territorio nacional. No creían en la necesidad de implantar escuelas, centros de salud o jueces de paz en cada rincón de sus "dominios". Tampoco creían que las personas que vivían allí aportaran nada bueno: por lo general se trataba de campesinos pobres, a menudo indígenas. En este sentido, los gobernantes de la capital consideraban suficiente mantener una buena relación con el cacique en turno para que mantuviera el orden en el territorio. Se trataba de un intercambio que beneficiaba a ambos. En Europa, por el contrario, los mandatarios crearon una administración sólida, presente en todas partes, pues necesitaban personas escolarizadas y con una identidad nacional definida a quienes cobrar impuestos, y sobre todo, movilizar en caso de enfrentamiento con los Estados vecinos, actividad recurrente si nos fijamos en la cantidad de guerras que hubo en el viejo continente durante el siglo XIX y la primera mitad del XX.

El contexto europeo es muy diferente a lo que acontece en Latinoamérica, donde ha habido pocos conflictos entre países, en general, episodios breves causados por disputas fronterizas. Así, los ejércitos en Latinoamérica nunca han sido de leva universal ni se han empleado para realizar "guerras totales" contra otros países. Los ejércitos latinoamericanos se han caracterizado por ser relativamente pequeños, socialmente estratificados y con la función de mantener el orden interno: disciplinar a los propios ciudadanos y garantizar el statu quo. Dicho de otra manera: la tarea principal de los ejércitos ha sido 
CUADRO 4. LA INTERACCIÓN CON EL ESTADO: LO BUENO, LO MALO Y LA EXTRACCIÓN

Lo bueno

Vivir en territorio mexicano

Tener una identidad

Ejercer el voto

Tener derechos

Hacer uso de servicios públicos, como

la escuela, el centro de salud, consumir

energía eléctrica o agua, ver la TV, tener

teléfono

Gozar de programas sociales
Lo malo

No hay seguridad

No hay claridad de si el Estado es la

solución o la culpa de la inseguridad

No se protege al trabajador

Dan demasiada propaganda
La extracción

Impuestos

Tiempo en los trámites

Pago de la energía

El voto

Información

Fuente: Elaboración propia.

reprimir a sus propios ciudadanos. Más allá de la presencia del Estado como medio de control y disciplina, es preciso ver hasta qué punto presta servicios con el fin de proveer bienes públicos y promover el bienestar de los ciudadanos.

A partir de la reflexión elaborada, comentada en el curso, se discutió la relación de los jóvenes con el Estado por medio de estas preguntas:

- ¿Cuál es la relación e interacción que tenían y han tenido con el Estado? ¿En qué espacios o acciones reconocen la presencia del Estado?

- ¿Cuáles son los beneficios que reciben del Estado, y a la vez, cuáles son los agravios o cargas que les exige la administración del mismo Estado?

También se les sugirió que preguntaran a sus adultos mayores, abuelos o tíos abuelos, cuál era la presencia del Estado en la comunidad cuando eran jóvenes. La relación e interacción que los estudiantes tienen - o perciben que tienen - con el Estado se expone en el cuadro 4. Se distingue entre lo que se considera "bueno" y "malo", y se expone la relación que se percibe como función de "extracción" por parte del Estado. Destaca la visión "bipolar" o contradictoria de los estudiantes sobre el Estado. Por un lado, creen que les otorga activos, como identidad, derechos, programas sociales e incluso servicios, como electricidad o telefonía - que no son titularidad del Estado- Por el otro, se critica al Estado por la mala calidad de los servicios, los bajos sueldos o la inseguridad. En cuanto a los temas vinculados a la “extracción”, es interesante ver que para los estudiantes no sólo es una carga abonar impuestos - a veces atribuyen al Estado pagos que hacen a empresas privadas-, también lo es perder tiempo en burocracia —que es mucha, según ellos- y dar información a agencias, como el Instituto Nacional de Estadística y Geografía, o que se les "reclame" el voto. Un tema relevante es que los jóvenes no tienen conocimiento de la función de "regulación" que ejerce el Estado. Muchas veces creen que las grandes empresas privadas — de agua, energía, telecomunicaciones, televisión - son parte del Estado, debido a que ejercen un dominio monopólico y omnipresente en el mercado.

Otra cuestión clave es cómo "aparece" el Estado en la cotidianidad de los estudiantes y de sus familias en su territorio. Las respuestas a esta cuestión apuntaron a tres maneras diferenciadas en las que el Estado se hace presente. La primera es por medio de autoridades, en particular el presidente municipal y los funcionarios locales. La segunda es por los programas sociales que impulsan las secretarías. La última es por la presencia del Ejército, que desde la administración de Felipe Calderón y su "guerra contra el narco" patrulla con mayor frecuencia en las comunidades. 
De estas tres formas, destaca la segunda, por la manera como se han elaborado las políticas públicas en los territorios periféricos y empobrecidos del país. Todos los estudiantes reconocieron programas sociales tanto del estado de Veracruz como del gobierno federal y todos dijeron que sus familiares eran beneficiarios de al menos dos programas. Entre los más citados estaban el Seguro Popular, Piso Firme, 70 y más, Apoyo a la Cadena Productiva de los Productores de Maíz y Frijol, programas de la Secretaría de Ganadería, Agricultura y Desarrollo Rural — como el Programa de Apoyos Directos al Campo (Procampo)—, becas de la Secretaría de Educación Pública de apoyo económico a jóvenes, las Misiones Culturales de la Secretaría de Educación de Veracruz, y Oportunidades, de la Secretaría de Desarrollo Social.

Otra cuestión relevante fue la comparación de su visión y experiencia de la actuación del Estado con la que tuvieron sus abuelos a su edad. A raíz de las entrevistas que hicieron los estudiantes a sus mayores, dedujeron que hace unos 60 años el Estado era una entidad con menor presencia en las comunidades rurales e indígenas de la zona. No había escuelas de educación básica ni centros de salud, no había luz ni telégrafo, las personas no tenían cédula de identidad, las carreteras eran malas y había mucho abandono. En esa época, la representación del Estado estaba en la ciudad y se personalizaba en el presidente municipal, el cual era una autoridad más temida que querida. Los mayores señalaron que en su juventud, hace más de medio siglo, el gobierno era "malo y lejano, y siempre beneficiaba a las personas ricas". Es importante señalar que los entrevistados destacan que en esos tiempos la gente era sana y no existían ni la inseguridad ni la criminalidad de hoy.

\section{La identificación de los problemas y la confianza en las instituciones}

Más allá de las reflexiones sobre la concepción de los estudiantes de la UVI acerca de la política y el poder, de haber identificado a los actores políticos más relevantes en su entorno y de debatir sobre la relación cotidiana que tienen con el Estado, en el curso también se habló de los problemas que más aquejaban al

\section{CUADRO 5. PRINCIPALES PROBLEMAS DE MÉXICO, LA COMUNIDAD Y LA FAMILIA}

\begin{tabular}{clll}
$\begin{array}{c}\text { Nivel de gravedad } \\
(\mathbf{1 - 9 )}\end{array}$ & \multicolumn{1}{c}{ México } & \multicolumn{1}{c}{ Comunidad } & \multicolumn{1}{c}{ Familia } \\
\hline 9 & Falta de empleo & Falta de empleo & Emigración \\
\hline 8 & Crimen organizado & Inseguridad & $\begin{array}{l}\text { Falta de programas } \\
\text { sociales }\end{array}$ \\
\hline 7 & $\begin{array}{l}\text { Corrupción } \\
\text { Pobreza }\end{array}$ & $\begin{array}{l}\text { Contaminación } \\
\text { Falta de agua } \\
\text { Calles sin pavimentar } \\
\text { Desorganización }\end{array}$ & $\begin{array}{l}\text { Poca y mala asistencia } \\
\text { sanitaria } \\
\text { Racismo } \\
\text { Inseguridad }\end{array}$ \\
\hline 6 & Injusticia & $\begin{array}{l}\text { Corrupción } \\
\text { Mala calidad de servicios }\end{array}$ & Ineficacia de la justicia \\
\hline 5 & Fraude & $\begin{array}{l}\text { Analfabetismo } \\
\text { Paternalismo }\end{array}$ & Violencia intrafamiliar \\
\hline
\end{tabular}

Fuente: Elaboración propia. 


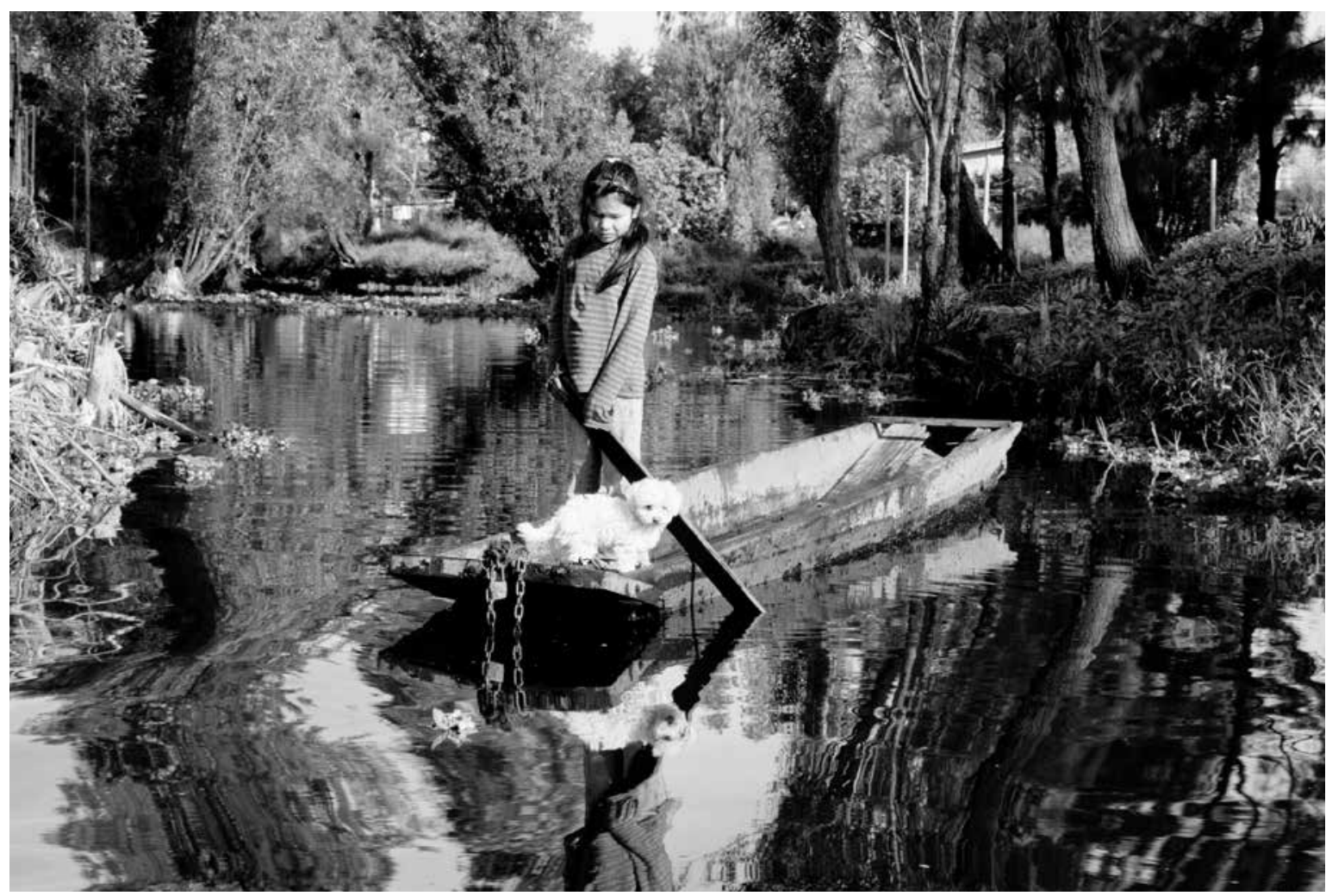

Prometeo Lucero • Una niña pasea en chalupa con su perro por los canales de Xochimilco. Ciudad de México, 16 de julio de 2011.

país y a su comunidad, y de cuánta confianza tienen ellos y las personas a las que entrevistaron en las instituciones. Los estudiantes respondieron cuestionarios y los aplicaron a cuatro personas de su confianza. Las preguntas fueron:

- ¿Cuáles son los principales problemas percibidos en el país y en sus entornos de proximidad?

- ¿Cuánto confían en las instituciones que, en teoría, deben resolver o gestionar dicho problema?

En cuanto a la primera pregunta, todos los estudiantes y entrevistados identificaron con facilidad los principales problemas que en su opinión aquejaban al país, a su comunidad y a su familia. Estos problemas se exponen por nivel de gravedad en el cuadro 5 , en el que 9 es el máximo nivel de gravedad y 5 un tema de preocupación. Es notoria la coherencia entre los principales problemas en los tres ámbitos: la falta de empleo en el país y la comunidad, y la emigración en la familia. Los problemas más sentidos en segundo lugar, en lo nacional y en la comunidad, son el crimen organizado y la inseguridad; y en el entorno familiar, la falta de ayudas. A partir del tercer problema, los que se exponen respecto de lo nacional son de carácter más genérico, en contraste con los que presentan más proximidad y están relacionados con temas muy cotidianos, tanto en la comunidad como en la familia. En el ámbito más íntimo, destaca la aparición de dos temas especialmente graves: el racismo y la violencia intrafamiliar. Sin embargo, según la percepción de los estudiantes, la política no es una actividad que ofrezca soluciones a estos problemas y le tienen muy 
poco aprecio. Con base en las entrevistas realizadas se observa cómo la política produce irritación y desconfianza en primer lugar y aburrimiento en segundo. De manera muy puntual, tres estudiantes, de un total de 22 , se muestran interesados y comprometidos con la política.

Por otro lado, los datos de la misma encuesta mostraron la poca confianza que les inspiran las instituciones presentes en la política y la sociedad, como se ve en el cuadro 6, en el que 1 es ninguna confianza y 9 total confianza. Incluso las dos instituciones más valoradas, la Iglesia católica y el ejército, registran sólo 4.85 y 4.80 sobre 9, respectivamente. Siguen dos instituciones de proximidad, el gobernador del estado y el presidente municipal, con 4.70 y 4.55 . Destaca la poca confianza que se tiene en el presidente de México, con 2.65, a quien se le percibe lejano y distante. Cabe señalar la relativamente buena posición de los sindicatos, en general denostados en el ámbito nacional, frente a la policía, los partidos políticos, y evidentemente, el narcotráfico.

Si se comparan los datos del cuadro 6 con la opinión agregada de todos los mexicanos, presentada en la tercera columna del cuadro 7, fruto de la Encuesta USAL-Colmex de 2011 (Martí i Puig, Ortega y Somuano, 2011; Martí i Puig et al., 2014) se constatan similitudes y discrepancias. Tanto en México como en la comunidad, las dos instituciones que mayor confianza generan son la Iglesia católica y el ejército, dos instancias jerárquicas y ajenas a la dinámica democrática. Destaca la mala opinión de los ciudadanos mexicanos acerca de las autoridades electas. En el caso de los entrevistados de la comunidad, se valora más a las autoridades próximas, como el gobernador y el presidente municipal, que al presidente de la república; este último es mejor valorado en la opinión agregada. Existe una coincidencia notoria en que la justicia y la policía no gozan de buena prensa. La primera es sensiblemente peor
CUADRO 6. CONFIANZA LOS ESTUDIANTES

Y HABITANTES EN SUS INSTITUCIONES

\begin{tabular}{lc}
\multicolumn{1}{c}{ Instituciones } & $\begin{array}{c}\text { En la comunidad } \\
\text { (1-9) }\end{array}$ \\
\hline Iglesia católica & 4.85 \\
\hline Ejército & 4.80 \\
\hline Gobernador & 4.70 \\
\hline Presidente municipal & 4.55 \\
\hline Sindicatos & 4.35 \\
\hline Administración de justicia & 3.55 \\
\hline Policía & 3.15 \\
\hline Presidente de México & 2.65 \\
\hline Partidos políticos & 2.45 \\
\hline Narcotráfico & 1.95 \\
\hline
\end{tabular}

Fuente: Elaboración propia.

valorada en la comunidad que en todo el país, al contrario de lo que ocurre con la policía. También los partidos son valorados de manera negativa, tanto en la comunidad como en el país. Los sindicatos, mal valorados en el ámbito nacional, tienen mejor prensa en la comunidad. Después de hablar de esta cuestión, los estudiantes expusieron que los sindicatos tienen un papel más relevante, permanente y activo en la vida de la comunidad que los partidos políticos, cuya presencia puntual se relaciona con las elecciones. Sobre este tema, los estudiantes de la UVI añadieron que "todos los políticos son iguales [...], la mayor parte engaña a las gentes de las comunidades con pequeños regalos o quieren comprar los votos de la gente con dinero". Señalaron que a veces los mismos políticos "venden despensas que teóricamente se dan gratis". En este sentido, los partidos sólo aparecen en el territorio cuando hay elecciones, mientras que los sindicatos son organizaciones presentes en la vida cotidiana y se puede recurrir a ellos. 
CUADRO 7. COMPARACIÓN DE LA VALORACIÓN DE INSTITUCIONES ENTRE LA COMUNIDAD Y EL PAÍS

En la comunidad

En México

\begin{tabular}{ll} 
Iglesia católica & Iglesia católica \\
\hline Ejército & Ejército \\
\hline Gobernador & Presidente municipal \\
\hline Presidente municipal & Administración de justicia \\
\hline Sindicatos & Policía \\
\hline Administración de justicia & Sindicatos \\
\hline Policía & Presidente de México \\
\hline Presidente de México & Gobernador \\
\hline Partidos políticos & Partidos políticos \\
\hline Narcotráfico & Narcotráfico \\
\hline
\end{tabular}

Fuente: Elaboración propia con base en los cuestionarios del curso y la Encuesta USAL-Colmex 2011.

\section{El papel que juega la multiculturalidad}

Antes de terminar, es indispensable añadir un epílogo sobre la multiculturalidad, uno de los ejes centrales de la UVI. Hemos señalado que los estudiantes de la sede Las Selvas, en concreto los 22 alumnos que siguieron el curso, vivían en comunidades de origen náhuatl o popoluca. Siete de ellos entendían y hablaban náhuatl y cuatro popoluca, lenguas vehiculares en los ámbitos familiar y comunitario. A pesar de ello, todos habían recibido educación primaria y secundaria en castellano, lo que redujo sus lenguas maternas al ámbito doméstico y al "cara a cara". No fue sino hasta su llegada a la UVI cuando percibieron que el náhuatl y el popoluca eran lenguas dignas de ser respetadas, valoradas y reivindicadas, incluso en el ámbito científico. En la UVI tenían cursos en estas lenguas y el náhuatl es obligatorio, por ser la lengua originaria más hablada en la zona. En la UVI, todos los profesores tienen un gran respeto por las culturas indígenas.
A pesar de ello, sólo algunos alumnos hablantes de estas lenguas las utilizaban en el aula y eran capaces de hacer presentaciones públicas, los demás no se atrevían a hablar en público en náhuatl o popoluca. Esta anécdota ilustra el fenómeno. En el curso de ciencia política, uno de los estudiantes, hablante de náhuatl, dijo que no era capaz de presentar su trabajo de investigación en su lengua materna porque nunca la había usado fuera de su entorno más próximo, sólo en dinámicas "cara a cara”. Ante esta dificultad, otra alumna, que también hablaba la lengua, le dijo que hiciera la presentación dirigiéndose a ella, "como si le hablara personalmente", y se sentó frente a él. La estrategia funcionó y la presentación del trabajo se realizó en náhuatl.

Los estudiantes señalaron que desde su llegada a la UVI habían tomado conciencia de la riqueza que significaba hablar una lengua indígena y de la necesidad de preservarla y dignificarla. Para tener constancia escrita sobre esta realidad, se preguntó a los estudiantes, y ellos a su vez a cuatro personas de sus comunidades, si creían que "la realidad pluricultural en México era (a) una realidad, (b) una riqueza, (c) nada importante o (d) no tenía opinión". De los entrevistados, $65.2 \%$ creía que era una riqueza, $17.3 \%$ que se trataba de una realidad, $4.3 \%$ que no era importante y $13.66 \%$ no tenía opinión. De este modo, se hizo evidente el orgullo, emergente entre los jóvenes, de las lenguas y culturas propias.

Sin embargo, aún queda mucho trabajo por hacer. La tarea de preservar y dignificar las culturas indígenas, así como de generar identidades complementarias que permitan reclamar derechos, no es fácil ni rápida. Con todo, la UVI es un espacio plurilingüe que da importancia a la variedad de saberes de las comunidades de origen de los estudiantes y pretende generar conciencia de los derechos relacionados con la multiculturalidad. Un ejercicio que el profesor de derecho de la Uvi pide a sus estudiantes da testimonio de ello. Los alumnos deben redactar peticiones en náhuatl a los ayuntamientos de la zona y enviarlas 


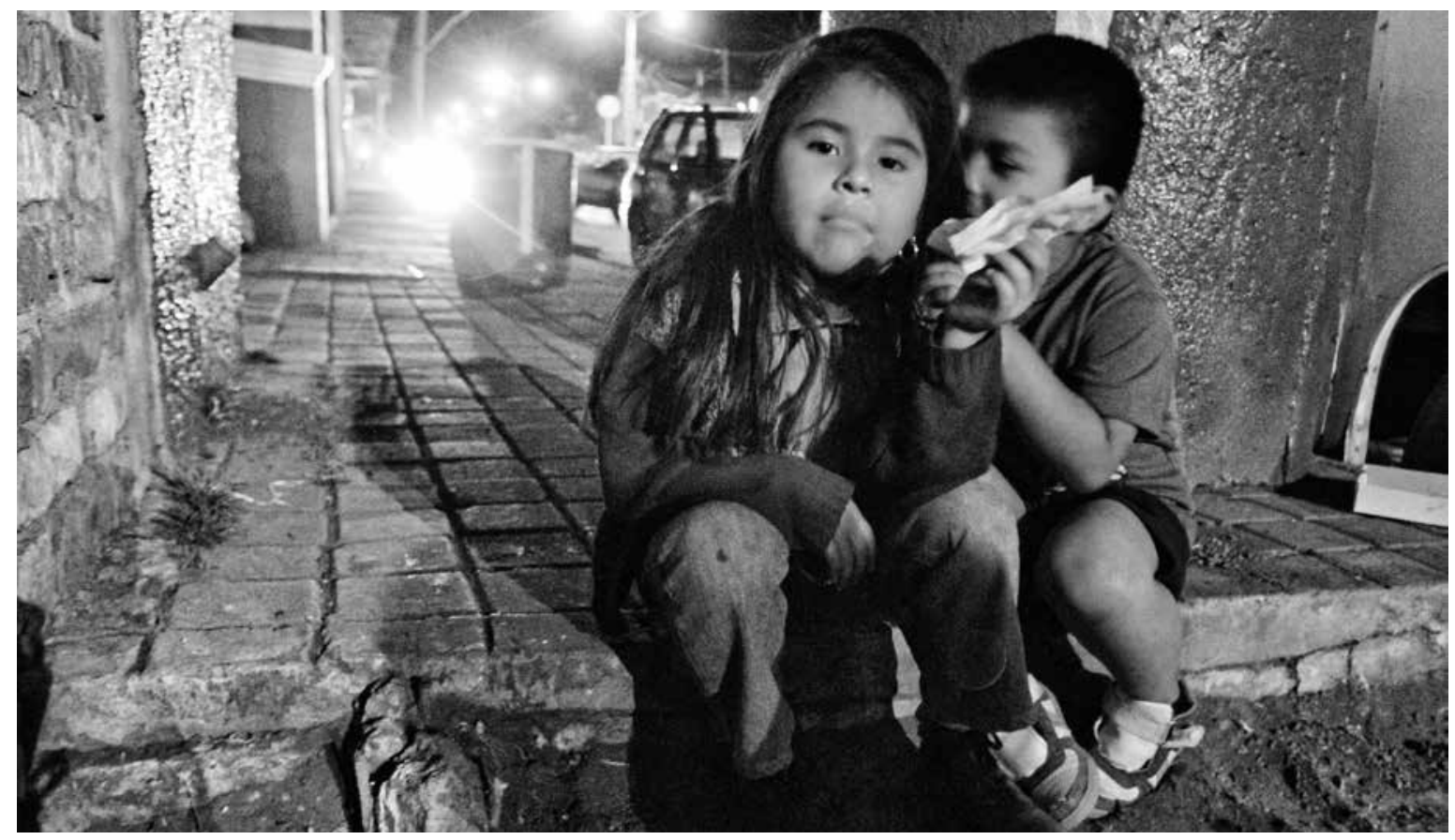

Consuelo PAgAza - Habitantes de Cherán durante las celebraciones del segundo aniversario del inicio de la lucha por la defensa de sus bosques. Michoacán, México, 2013.

hasta recibir respuesta oficial, también en náhuatl. Al final, las respuestas oficiales llegaron en náhuatl.

\section{Una breve interpretación de los hallazgos}

A modo de conclusión, y a la luz del contenido expuesto en este texto, se destaca que entre los jóvenes que siguieron el curso aún pervive una concepción del poder muy vinculada a la tradición, al patriarcado y a los recursos - dinero y tierras - en el entorno íntimo de la familia, y en menor medida, en la comunidad. Con todo, es posible observar pequeños cambios o elementos de ruptura en dicha concepción en los ámbitos familiar y comunitario. En la familia, todo parece indicar que la transformación se realizará a raíz de las nuevas percepciones de las mujeres jóvenes, quienes ya no se resignan a un rol subordinado y dependiente del varón. A esta actitud reivindicativa de las mujeres se añade el fenómeno de la migración, que ha supuesto la ausencia de la figura del "jefe del hogar varón”, y con ello, la aparición de nuevos papeles de responsabilidad y autoridad para las mujeres. En cuanto al poder en la comunidad, si bien se desprende de los diálogos y encuestas que las organizaciones hegemónicas — partidos y sindicatos- de la zona tienen dinero y recursos, también se aprecia que los jóvenes identifican la importancia de los colectivos sociales organizados cuyos recursos no son sólo el dinero o la conexión con el statu quo, sino la movilización y la acción colectiva.

A pesar de reconocer nuevos actores emergentes, es preciso señalar que la confianza que muestran los estudiantes en las instituciones y las organizaciones políticas es muy baja y su participación en los eventos políticos limitada, no obstante la notoria coincidencia en los principales problemas de la comunidad, la región y el país. 
Uno de los temas más relevantes de este ensayo era la manera como los jóvenes perciben su relación con lo público, es decir, con el Estado y sus instituciones. Destaca una visión contradictoria: a veces complaciente, a veces hipercrítica, y otras confusa o de desconocimiento. La visión complaciente señala al Estado como la institución que provee identidad, políticas sociales, programas de desarrollo, integración, símbolos y orgullo nacional. La visión hipercrítica percibe al Estado como culpable de la compra de votos, de los bajos sueldos, de la desigualdad o de la inseguridad. El desconocimiento de los estudiantes respecto del Estado se basa en que hay muy poca información sobre el papel de regulación que corresponde a las instituciones o a la dejación de funciones del Estado mexicano en algunos temas que se desprenden de la privatización de políticas sectoriales clave - como la energía o las telecomunicaciones- y de la inexistencia de una televisión nacional pública. En cuanto a la confusión que genera el desempeño del Estado entre los entrevistados, ésta proviene de la indefinición de si realmente el Estado y sus representantes trabajan para impulsar el desarrollo social, el bien común o la equidad — como dice la propaganda institucional - o para mantener el statu quo e incrementar el poder de los poderosos. Tampoco hay claridad acerca de la veracidad de la lucha de las fuerzas armadas, jueces y políticos contra el narcotráfico y el crimen organizado, como se anuncia en los medios. La percepción del Estado como un ente contradictorio, confuso y con múltiples rostros —algunos buenos y otros terribles — probablemente no es fruto de la ignorancia de los estudiantes, sino lo contrario. Un conocimiento profundo, cotidiano y subalterno del Estado, en la periferia de éste, sólo puede llevar a tener una opinión ambigua, pues el Estado también lo es (Auyero, Burbano y Berti, 2014). ${ }^{5}$

Ante las respuestas en apariencia contradictorias de los estudiantes, uno podría preguntarse, ¿ipor qué no hay una visión más integrada y consistente de su opinión sobre el Estado y la ciudadanía? Una posible interpretación es que de verdad en las zonas periféricas de México no existe propiamente el estatus de ciudadano ni un Estado en los términos clásicos weberianos. Como señala la teoría decolonial (Chatterjee, 2008; Mignolo, 2003; 2007), en muchos países del sur los habitantes se identifican con la idea de la "comunidad imaginada" de Anderson (1993), es decir, que la población se identifica con la "nación mexicana" entendida como adhesión a la bandera, el himno, los símbolos y la historia aprendida, pero detestan a los políticos y no se reconocen con los poderes ni con las instituciones del Estado porque los perciben distantes y hostiles. Ese fenómeno, sin duda, no es fruto del desconocimiento ni de la falta de escolaridad, sino de la experiencia cotidiana.

Por último, es importante incluir la opinión de los estudiantes sobre el curso. A raíz de la evaluación y de los comentarios que surgieron, los estudiantes expusieron que al comienzo se inscribieron por curiosidad, pero que después les interesó por dos razones. La primera fue la vinculación entre teoría y vida cotidiana por medio de las tareas entre sesión y sesión, muchas de las cuales se basaban en la realización de entrevistas a familiares, conocidos y personas de la comunidad. La segunda razón fue que gracias al taller los estudiantes se dieron cuenta de que las opciones de su licenciatura tienen una intensa relación con la política y las políticas públicas; si desean desempeñar labores para mejorar el desarrollo de sus comunidades, deben tener en cuenta tanto la presencia de los actores e instituciones en la zona, como la actitud de las personas hacia lo público y lo común. D

5

Durante los últimos años, se ha empezado a trabajar sobre el tema del Estado como un ente contradictorio y con alianzas con el mundo del delito y el crimen. El trabajo de Auyero, Burbano y Berti (2013) sobre la "institucionalidad en los márgenes" en Argentina es una excelente contribución al debate. En México, destaca la aparición de literatura que habla de la democratización desigual del país, según las entidades territoriales (Gibson, 2004). 


\section{Bibliografía}

Almond, Gabriel y Sidney Verba, 1970, La cultura cívica, Euramérica, Madrid.

Anderson, Benedict, 1993, Comunidades imaginadas: reflexiones sobre el origen y la difusión del nacionalismo, Fondo de Cultura Económica, México.

Auyero, Javier, Agustín Burbano de Lara y María Fernanda Berti, 2014, "Violence and the State at the Urban Margins", en Journal of Contemporary Ethnography, vol. 43, núm. 1, pp. 94-116.

Centeno, Miguel Ángel, 2002, Blood and Debt. War and the Nation State in Latin America, The Pennsylvania State University Press, Pensilvania. Centeno, Miguel Ángel y Agustín Ferraro (eds.), 2013, State and Nation Making in Latin America and Spain. Republics of the Possible, Cambridge University Press, Cambridge.

Chatterjee, Partha, 2008, La nación en tiempo heterogéneo, Siglo XXI Editores, Buenos Aires.

Dietz, Gunther, 2008, "La experiencia de la Universidad Veracruzana Intercultural”, en Daniel Mato (coord.), Diversidad cultural e interculturalidad en la educación superior: experiencias en América Latina, Organización de las Naciones Unidas para la Educación, la Ciencia y la Cultura-Instituto Internacional para la Educación Superior en América Latina y el Caribe, Caracas, pp. 359-370.

—_, 2012, Multiculturalismo, interculturalidad y diversidad en educación: una aproximación antropológica, Fondo de Cultura Económica, México.

Dijk, Teun van, 2001, El discurso como interacción social, Gedisa, Barcelona.

“Encuesta usAL-Colmex”, 2011, en Salvador Martí i Puig, Reynaldo Yunuen Ortega Ortiz y María Fernanda Somuano Ventura (eds.), La democracia en México. Un análisis a 10 años de la alternancia, Bellaterra, Barcelona.

Gibson, Edward, 2004, "Subnational Authoritarianism: Territorial Strategies of Political Control in Democratic Regimes", ponencia presentada en la 2004 Annual Meeting of the American Political Science Association.

Martí i Puig, Salvador, 2009 “Los múltiples debates (y realidades) de la democracia en América Latina”, en Revista cIDOB d’Afers Internacionals, núm. 85-86, pp. 57-74.

__. 2012, "Ciudadanía y cultura política en México a dos sexenios de la 'alternancia”, en Foro Internacional, vol. LII, núm. 4, pp. 868-884.

Martí i Puig, Salvador, Reynaldo Yunuen Ortega Ortiz y María Fernanda Somuano Ventura (eds.), 2011, La democracia en México. Un análisis a 10 años de la alternancia, Bellaterra, Barcelona.

Martí i Puig, Salvador et al. (eds.), 2014, Democracy in Mexico: Attitudes and Perceptions of Citizens at National and Local Level, Institute of Latin American Studies/Palgrave, Londres.

Mateos Cortés, Laura y Gunther Dietz, 2014, "Resignificaciones locales de los discursos transnacionales de educación superior intercultural en Veracruz", en Revista Mexicana de Investigación Educativa, vol. 19, núm. 60, pp. 45-71.

Mato, Daniel (coord.), 2008, Diversidad cultural e interculturalidad en la educación superior: experiencias en América Latina, Organización de las Naciones Unidas para la Educación, la Ciencia y la Cultura-Instituto Internacional para la Educación Superior en América Latina y el Caribe, Caracas.

Méndez, Juan E., Guillermo O’Donnell y Paulo Sérgio Pinheiro (comps.), 1996, La (in)efectividad de la ley y la exclusión en América Latina, Paidós, Buenos Aires.

Mignolo, Walter, 2003, Historias locales/diseños globales: colonialidad, conocimientos subalternos y pensamiento fronterizo, Akal, Madrid.

_ - 2007, "El pensamiento decolonial: desprendimiento y apertura. Un manifiesto", en Santiago Castro-Gómez y Ramón Grosfoguel (eds.), El giro decolonial: reflexiones para una diversidad epistémica más allá del capitalismo global, Siglo del Hombre, Bogotá.

Rovira, Guiomar, 1997, Mujeres de maíz, Era, México.

Universidad Veracruzana Intercultural (UvI), 2005, Programa general, Universidad Veracruzana Intercultural, Xalapa.

—_, 2007, Licenciatura en gestión intercultural para el desarrollo: programa multimodal de formación integral, Universidad Veracruzana Intercultural, Xalapa.

Vallès, Josep Maria y Salvador Martí i Puig, 2000, Curso de ciencia política, Editorial de la Universitat Oberta de Catalunya, Barcelona.

_ 2015, Ciencia política. Un manual, Ariel, Barcelona.

Weber, Max, 2003 [1922], Economía y sociedad, Fondo de Cultura Económica, México. 